không có trường hợp nào S. pyogenes kháng với penicillin [8].

\section{KẾT LUÂN}

Bệnh nhân bi bênh chốc trong mẫu nghiên cứu chủ yếu là chốc không bóng nước, với tỷ lệ $61,8 \%$, kế đến là chốc loét $25,5 \%$ và chốc bóng nước 8,6\%.

Tác nhân gây bệnh chủ yếu là $S$. aureus với tỷ lệ là $63,6 \%$ trong các trường hợp cây dương tính.

Tình trạng đề kháng với kháng sin penicillin của $\mathrm{S}$. aureus là rất cao $(98,5 \%)$, kế đến là erythromycin (81,5\%), clindamycin $(69,2 \%)$. Tuy nhiên, vi trùng này vấn còn nhạy cao với oxacillin $(61,8 \%)$, cefuroxime $(83,1 \%)$ và tỷ lệ MRSA là $13,8 \%$. Riêng 2 trường hợp $S$. pyogenes đều nhạy cảm với penicillin.

\section{TÀI LIỆ THAM KHẢO}

1. Mai Thị Liên (2016), "Đă̆c điểm lâm sàng, yễu tố liên quan và hiệu quả điều trị bệnh chốc bằng cefixim kết hợp với fucidin", Luận văn thạc sĩ y hơc, Trường đại học Y Hà Nội, Hà Nội,

2. Đố Thị Thúy Nga (2011), "Tiêu chuấn đọc kết quả kháng sinh đồ và MIC", Qui trình thao tác chuẩn về thử nghiệm tính nhạy cám kháng sinh (21),
3. Trân Nguyên Ánh Tú (2016), "Tình trạng kháng thuốc in vitro của Staphyloccocus aureus và Streptococcus pyogennes gây bênh chốc ở trẻ em đến khám tại Bệnh viện Da liễu thành phố Hồ Chí Minh", Tạp chí Y học Thành Phố Hồ Chí Minh, 20(2), tr.63-69.

4. Cole C. \& Gazewood J. (2007), "Diagnosis and treatment of impetigo ", Am Fam Physician 75(6), pp.859-864.

5. James G.H. Dinulos (2020), "Impetigo", Habif's Clinical Dermatology: A Color Guide in Diagnosis and Therapy, Elsevier, pp. 331-340.

6. Vohra $H$ Kumar $R$, Chakraborty $A$, et a (2009), "Epidemiology of group A streptococcal pharyngitis \&impetigo: a cross-sectional \& follow up study in a ruralcommunity of northern India", The Indian journal of medicalresearch,130(6), pp. 765-771.

7. Kong $F$ Liu $Y$, Zhang $X$, et al (2009), "Antimicrobial susceptibility of Staphylococcus aureus isolated from children with impetigo in China from 2003 to 2007 shows communityassociated methicillin-resistant Staphylococcus aureus to be uncommon and heterogeneous", The British journal of dermatology, 161(6), pp. 1347-1350.

8. Heilmann KP Richter SS, Beekmann SS (2015), "Macrolide-resistant Streptococcus pyogenes in the UnitedStates, 2012-2013", Clinical Infection Diseases,41(1), pp. 599 - 608.

\title{
KẾT QUẢ SớM PHẪU THUÂT CẮT U MÔ ĐỆM (GIST) DẠ DÀY TẠI KHOA NGOẠI - BÊ̂NH VIỆN BẠCH MAI
}

\section{Lun Panha ${ }^{1}$, Trần Quế Sơnn ${ }^{1,2}$, Trần Hiếu Học ${ }^{1,2}$}

\section{TÓM TẮT}

Mục tiêu: mô tả một số đặc điểm lâm sàng, cận lâm sả̉ng và kết quả phâ̂u thuât u mô đêm cứa da dày. Đối tượng và phương pháp nghiên cứu: mổ tả loạt ca bểnh, những trường hợp u mô đệm của da dày được phẫu thuật tại bệnh viện Bạch Mai từ 2016 đên 2019. Kết quả: 50 bênh nhẩn với tuổi trung bình $56,3 \pm 12,6$ và tỉ lệ nam/nữ là 0,79 . Đau bụng là triệu chứng thường gặp $(94 \%)$, nội soi thây có loét trên u $52 \%$ và vị trí u chủ yếu ở hang vị và thân vị $(74 \%)$; cắt lớp vi tính thấy kích thước u $9,2 \pm 9,0 \mathrm{~cm}$, bờ đều $88 \%$, ngấm thuốc manh $72 \%$; hai dâuu ân CD117 và CD 34 thấy $100 \%$. Cắt da dày hình chêm là kỹ thuật dùng nhiêuu nhất $76 \%$; thời gian trung tiện $1,9 \pm 0,7$ ngày, rút sonde dạ dày $2,5 \pm 1,3$ ngày, cho ăn trở lại $3,2 \pm 1,2$ ngày, nằm viện sau mổ trung bình 6,2 ngày. Tai biến chảy máu trong mổ $2(4,0 \%)$, biến chứng

\footnotetext{
${ }^{1}$ Trường Đại học Y Hà Nội

${ }^{2}$ Khoa Ngoại bệnh viện Bạch mai

Chịu trách nhiệm chính: Trần Hiếu Học.

Email: hieuhoc1305@gmail.com

Ngày nhận bài: 26/6/2021

Ngày phản biện khoa học: 30/7/2021

Ngày duyệt bài: 19/8/2021
}

nhiễm trùng vết mổ 4 (8,0\%). Kết luận: Chẩn đoán bệnh chủ yếu dựa vào nội șoi, chẩn đoán hình ảnh và xác định bằng hóa mô miển dịch. Phẫu thuật có kết quả sớm tốt, song cần theo dõi lâu dài thêm.

Tư khóa: U mô đệm đường tiêu hóa, dạ dày, phẫu thuật.

\section{SUMMARY}

\section{EARLY RESULTS OF SUGICAL TREAMENT OF GASTROINTESTINAL STROMAL TUMOR LOCALIZED IN THE STOMACH AT SURGERY, BACH MAI HOSPITAL}

Objectives: To describe some clinical, paraclinical features and surgical results of this disease. Material and methods: A descriptive study of the case series of GIST localized in the stomach operated at Bach Mai hospital from 2016 to 2019. Results: There was 50 patients with mean age $56.3 \pm 12.6$ and male/female ratio of 0,79 . The abdominal pain was common symptom (94\%), the endoscopy showed mucosal ulceration $52 \%$ and tumor locations were primarily at body and pyloric antrum (74\%); computed tomography showed the tumor size of $9.2 \pm 9.0 \mathrm{~cm}$, regular margins $88 \%$, two immune markers CD117 and $C D 34$ were present in $100 \%$. The wedge gastrectomy was most commonly used technique 
(76\%); mean time of gas was of $1.9 \pm 0.7$ days, gastric sonde removal of $2.5 \pm 1.3$ days, re-feeding $3.2 \pm 1.2$ days, length of hospital stay of 6.2 day. The peroperative bleeding was of $4.0 \%$, wound infection of $8.0 \%$. Conclusion: The diagnosis was mainly based on endoscopy and computed tomography and the accuracy was on immunohistochemistry. Early results are usually good, but further long-term follow-up was needed.

Keywords: Gastrointestinal stromal tumor, stomach, surgery.

\section{I. ĐĂT VẤN ĐỀ}

U mô đệm đường tiêu hóa (GIST: Gastrointestinal Stromal Tumor) là u trung mô ác tính thường gặp của đường tiêu hoá, chiếm khoảng 1 - 3\% các u ác tính của ống tiêu hóa; trong đó vị trí tại dạ dày là thường gặp nhất với tỷ lệ 39-70\%[1,2]. Các triệu chứng lâm sàng thường mơ hồ và không điển hình, thậm chí không có biểu hiện gì khi u nhỏ nên dễ bị bỏ sót. Phần lớn bệnh nhân được phát hiện ở giai đoạn muộn hoặc phát hiện tình cờ qua nội soi tiêu hóa và các phương tiện chẩn đoán hình ảnh khác. Việc chẩn đoán xác định chủ yếu dựa vào kết quả giải phẫu bệnh và hóa mô miễn dịch $[2,3]$.

Điều trị phẫu thuật vẫn là phương pháp điều trị triêtt căn căn bản. Gần đây nhờ sự phát triển của kỹ thuật mổ và các trang thiết bị y tế đồng thời trình độ của phẫu thuật viên ngày càng được cải thiện đã đem lại nhứng kết quả tốt hơn trong điều trị GIST dạ dày $[4,5]$. Để cung cấp các thông tin phuc vư cho quá trình chẩn đoán và điều trị cho bệnh nhân GIST, chúng tôi thực hiện nghiên cứu này với mục tiêu: Mô tả một số đặc điểm lâm sàng, cận lâm sàng và kết quả sớm điều trị phẫu thuẩt các trường hợp u mô đệm (GIST) của dạ dày tại khoa Ngoại - Bệnh viện Bạch Mai giai đoạn 2016-2020.

\section{II. ĐỐI TƯỢNG VÀ PHƯƠNG PHÁP NGHIÊN CỨU}

2.1. Đối tượng nghiên cứu. 50 bệnh nhân trên 18 tuổi, được điều trị phẫu thuật tại khoa Ngoại Bệnh viện Bạch Mai từ tháng 01 năm 2016 đến tháng 12 năm 2020, có khối u ở dạ dày trên nội soi, được chẩn đoán xác định bằng mô bệnh học là GIST và hóa mô miễn dịch dương tính với CD-117 và/hoặc CD34; loại trừ khỏi nghiên cứu bệnh nhân: có các ung thư đường tiêu hóa khác, có tiền sử mổ cắt da dày.

\subsection{Phương pháp nghiên cứu}

- Nghiên cứu mô tả loạt ca bệnh với cách chọn mẫu thuận tiện.

- Thu thập thông tin về các đặc điểm: lâm sàng (tiền sử nội ngoại khoa, triệu chứng lâm sàng (đau bụng, sốt, đại tiện phân đen, sờ thây khối u), chẩn đoán hình ảnh gồm nội soi dạ dày và chụp cắt lớp vi tính. Thông tin về phẫu thuật và kết quả điều trị: kỹ thuật mổ, thời gian mổ, thời gian trung tiện, thời gian nằm viện sau mố, tai biến và biến chứng chính.

- Tiêu chuẩn chẩn đoán u mô đệm dựa và giải phẫu bệnh: hóa mô miễn dịch CD117, CD34.

- Phân tích và xử lý số liệu: Sử dụng phần mềm SPSS 22.0, Test kiểm định: $\chi^{2}, T$ - test.

\section{KẾT QUẢ NGHIÊN CỨU}

Nghiên cứu trên 50 bệnh nhân với tuổi trung bình $56,3 \pm 12,6$ tuổi, thấp nhất là 33 tuổi và cao nhất là 86 tuổi, có 22 nam và 28 nữ, tỉ lệ nam/nữ là 0,79 .

\section{1. Đặc điểm lâm sàng và cận lâm sàng}

Bảng 1. Đặc điểm lâm sàng $(n=50)$

\begin{tabular}{|c|c|c|c|c|}
\hline \multicolumn{2}{|c|}{ Triệu chứng } & $\mathbf{n}$ & $\mathbf{\%}$ \\
\hline \multirow{4}{*}{$\begin{array}{c}\text { Đau } \\
\text { bụng }\end{array}$} & \multirow{3}{*}{ Vị trí } & Thượng vị & 41 & 87,2 \\
\cline { 3 - 5 } & Quanh rốn & 05 & 10,6 \\
\cline { 2 - 4 } & Tính & Hạ sườn trái & 01 & 2,1 \\
\cline { 2 - 4 } & chất & Lơ̂n & 29 & 61,7 \\
\cline { 2 - 4 } & \multicolumn{2}{|c|}{ Không đục } & 18 & 38,3 \\
\hline \multicolumn{3}{|c|}{ Gây sút cân } & 3 & 6,0 \\
\hline \multicolumn{2}{|c|}{ Đâyy bụng, chướng bụng } & 01 & 2,0 \\
\hline \multicolumn{3}{|c|}{ Nồn, buồn nôn } & 01 & 2,0 \\
\hline \multicolumn{3}{|c|}{ Đại tiện phân đen } & 01 & 2,0 \\
\hline \multicolumn{3}{|c|}{ Sờ thấy khối u } & 04 & 8,0 \\
\hline \multicolumn{3}{|c|}{ Thiếu máu } & 07 & 14,0 \\
\hline
\end{tabular}

Nhận xét: Đau bụng là triệu chứng lâm sàng phổ biển nhất $(94,0 \%)$, chủ yếu ở vùng thượng vị $(87,2 \%)$, phần nhiều đau thành cơn $(61,7 \%)$. Các triệu chứng khác đều gặp với tỉ lệ thấp.

Bảng 2. Hình ảnh nội soi dạ dày và cắt lớp vi tính $(n=50)$

\begin{tabular}{|c|c|c|c|c|}
\hline \multicolumn{3}{|c|}{ Đặc điếm } & \multirow{2}{*}{$\frac{\mathbf{n}}{24}$} & \multirow{2}{*}{$\begin{array}{c}\% \\
48,0 \\
\end{array}$} \\
\hline \multirow{8}{*}{$\begin{array}{l}\text { Nội } \\
\text { soi } \\
\text { dạ } \\
\text { dày }\end{array}$} & \multirow{2}{*}{$\begin{array}{c}\text { Niêm } \\
\text { mạc vị } \\
\text { trí khối u }\end{array}$} & \begin{tabular}{|c|} 
Bình thường \\
\end{tabular} & & \\
\hline & & Loét, chảy máu & 26 & 52,0 \\
\hline & \multirow{6}{*}{ Vị trí u } & Thân vị & 13 & 26,0 \\
\hline & & Tâm vị & 07 & 14,0 \\
\hline & & Bờ cong lớn & 01 & 21,0 \\
\hline & & Bờ cong nhỏ & 04 & 8,0 \\
\hline & & Hang vi & 24 & 48,0 \\
\hline & & Môn vị & 01 & 2,0 \\
\hline \multirow{6}{*}{$\begin{array}{c}\text { Cắt } \\
\text { lớp } \\
\text { vi } \\
\text { tính }\end{array}$} & \multirow{4}{*}{ Khối u } & Kích thước (cm) & $9,2 \pm 9$, & $(2 \div 15)$ \\
\hline & & Bờ đều & 44 & 88,0 \\
\hline & & $\begin{array}{l}\text { Hoại tứ trung } \\
\text { tâm }\end{array}$ & 02 & 4,0 \\
\hline & & $\begin{array}{l}\text { Ngấm thuốc } \\
\text { mạnh }\end{array}$ & 36 & 72,0 \\
\hline & \multirow[b]{2}{*}{ Di căn } & Dạ dày & 01 & 2,0 \\
\hline & & $\begin{array}{l}\text { Đại tràng } \\
\text { ngang }\end{array}$ & 02 & 4,0 \\
\hline
\end{tabular}


Tụy

\begin{tabular}{l|l}
01 & 2,0 \\
\hline
\end{tabular}

Nhân xét: Trên hình ảnh cắt lớp vi tính kích thước khối u trung bình 9,2 $\pm 9,0 \mathrm{~cm}$, nhỏ nhất là $2 \mathrm{~cm}$ và lớn nhất là $15 \mathrm{~cm}$ và có 4 trường hợp có biểu hiện di căn.

Bảng 3. Đặc điểm hóa mô miễn dịch $(n=50)$

\begin{tabular}{|c|c|c|}
\hline Đặc điếm & Tần số (n) & Tỷ lệ \% \\
\hline CD117 & 50 & 100,0 \\
\hline CD34 & 50 & 100,0 \\
\hline DOG1 & 46 & 92,0 \\
\hline Desmin & 18 & 36 \\
\hline SMA & 44 & 88,0 \\
\hline S100 & 8 & 16,0 \\
\hline CK & 7 & 14,0 \\
\hline
\end{tabular}

Nhận xét: Hai dấu ấn miền dịch CD117 và CD34 có ở tất cả các trường hợp.

3.2. Kết quả phẫu thuât

Bảng 4. Phương pháp phẫu thuật $(n=50)$

\begin{tabular}{|c|c|c|c|}
\hline $\begin{array}{c}\text { Phương pháp } \\
\text { phẩu thuật }\end{array}$ & Mổ mở & $\begin{array}{c}\text { Mố noôii } \\
\text { soi }\end{array}$ & Tổng \\
\cline { 2 - 4 } & $\mathbf{n ~ ( \% )}$ & $\mathbf{n ~ ( \% )}$ & $\mathbf{n ~ ( \% )}$ \\
\hline Cắt dạ dày hình & 26 & 12 & 38 \\
chêm & $(68,4)$ & $(100)$ & $(76,0)$ \\
\hline Cắt đoạn dạy dày & $08(21,1)$ & 0 & $08(16,0)$ \\
\hline Cắt dạ dày toàn bộ, & 04 & 0 & 04 \\
mở rộng & $(10,5)$ & 0 & $(8,0)$ \\
\hline Tổng & $\begin{array}{c}\mathbf{3 8} \\
(\mathbf{1 0 0})\end{array}$ & $\begin{array}{c}\mathbf{1 2} \\
\mathbf{( 1 0 0 )}\end{array}$ & $\begin{array}{c}\mathbf{5 0} \\
\mathbf{( 1 0 0 )}\end{array}$ \\
\hline
\end{tabular}

Nhân xét: 12 bênh nhân mố nôi soi được cắt da dày hình chêm, không có bệnh nhân nào mổ nội soi phải chuyển mổ mở.

Bảng 5. Kết quả sớm sau phẫu thuât $(n=50)$

\begin{tabular}{|c|c|c|}
\hline \multicolumn{3}{|c|}{ Diên biến sau mố } \\
\hline Thời gian (ngày) & Trung bình & Độ lệch \\
\hline Trung tiện & 1,9 & 0,7 \\
\hline Rút sonde dạ dày & 2,5 & 1,3 \\
\hline Cho ăn trở lại & 3,2 & 1,2 \\
\hline Thuốc giảm đau & 2,3 & 0,7 \\
\hline Nằm viện sau mố & 6,2 & 3,7 \\
\hline \multicolumn{3}{|c|}{ Tai biến và biến chứng } \\
\hline Tai biến, biến chứng & Tân số & Tỉ lệ \% \\
\hline Chảy máu trong mố & 02 & 4,0 \\
\hline Nhiềm trùng vết mố & 04 & 8,0 \\
\hline
\end{tabular}

Nhân xét: Có 2 trường hợp tai biến trong mổ là chảy máu và 4 trường hợp biến chứng sau mổ là nhiểm trùng vết mổ.

\section{BÀN LUẬN}

Kết quả nghiên cứu của chúng tôi cho thây đau bụng là triệu chứng lâm sàng phổ biến nhất ở bệnh nhân nghiên cứu (94,0\%). Các triệu chứng lâm sàng khác hiếm gặp hơn như thiếu máu $(14,0 \%)$, sờ thấy khối u $(8,0 \%)$, đại tiện phân đen $(8,0 \%)$, gầy sút cân $(2,0 \%)$.

Kết quả nghiên cứu của chúng tôi tương tự với kết quả của nhiều tác giả cho rằng phần lớn GIST không có triệu chứng và được phát hiện một cách tình cờ $[2,3]$. Trong nghiên cứu 35 bệnh nhân u mô đệm đường tiêu điều trị tại bệnh viện Bạch Mai, tác giả Mai Trọng Khoa ghi nhận triệu chứng đau bụng chiếm tỉ lệ nhiêu nhất, khoảng 2/3 số trường hợp [5]. Triệu chứng đau bụng có thể giải thích do sự phát triển nhanh của u gây chèn ép khoang phúc mạc hoặc do sự tiến triển xâm lấn các tạng lân cận, thậm chí có thể do u đã di căn gan hoặc phúc mạc. Kết quả tất cả bệnh nhân trong nghiên cứu của chúng tôi đều có triệu chứng khi đến khám bệnh. Chúng tôi nhận thấy, có nhiều bệnh nhân đau bụng ở những vị trí không tương xứng với khối u như đau bụng thành cơn quanh rốn hoặc đau bụng thay đổi vị trí kèm rối loạn đại tiện, đầy bụng, chướng bụng, đây có thể là triệu chứng của các bệnh lý khác kèm theo và cũng là nguyên nhân khiến bệnh nhân phải đi khám.

Ngoài ra, các lý do khác như triệu chứng của xuất huyết tiêu hóa (XHTH) hay sờ thấy khối u trong nghiên cứu của chúng tôi là hiếm gặp. Kết quả này thấp hơn so với nghiên cứu của Bùi Trung Nghĩa với tỉ lệ XHTH là 21,4\% [4]. Nguyên nhân có thể trong thời gian gần đây, $y$ tế tuyến cơ sở đặc biệt các bệnh viện tỉnh có nhiều tiến bộ. Nhiều bệnh nhân vào bệnh viện tuyến cơ sở để cấp cứu vì xuất huyết tiêu hóa được thực hiên phẫu thuật ngay tại đây, ít có bệnh nhân phải chuyển tuyến lên bệnh viện Bạch Mai.

Chụp cắt lớp vi tính (CLVT) được coi là phương tiện có giá trị chẩn đoán cơ bản đối với GIST; có giá trị cao không chỉ trong chẩn đoán mà còn trong theo dõi, đánh giá đáp ứng điều trị và tái phát sau mổ. Kết quả nghiên cứu của chúng tôi cho thấy, trên hình ảnh cắt lớp vi tính kích thước khối u trung bình 9,2 $\pm 9,0 \mathrm{~cm}$, trong đó nhỏ nhất là $2 \mathrm{~cm}$ và lớn nhất là $15 \mathrm{~cm}$. Kích thước u GIST trong nhiều nghiên cứu là khác nhau,với kích thước trung bình từ 4,4 đến 18,8 $\mathrm{cm}$ [6] [1]. Kích thước u trung bình trong nghiên cứu tại Litva năm 2014 của Poškus và cộng sự cũng chỉ 4,4 cm [2]. Kích thước khối u trong các nghiên cứu có sự khác biệt như vậy có thể do đối tượng nghiên cứu có sự khác biệt và sự phát triển của nội soi tiêu hóa của từng khu vực cũng khác nhau mà nội soi có vai trò quan trọng trong chẩn đoán sớm các khối u dạ dày. Về tính chất của khối u, trong nghiên cứu của chúng tôi, phần lớn khối u có bờ đều $(88,0 \%)$ và ngấm thuốc 
mạnh $(72,0 \%)$, ít có hoại tử trung tâm $(4,0 \%)$. Phát hiện di căn dạ dày $(2,0 \%)$, đại tràng ngang $(4,0 \%)$, tụy $(2,0 \%)$. Kết quả này tương đồng với nhiêu nghiên cứu của các tác giả khác [2],[4]. Theo đó, GIST nguyên phát thường là một khối tăng tỷ trọng đơn độc, ranh giới rõ, tăng sinh mạch và thường không đồng nhất do hoại tử trung tâm, chảy máu trong u hay thoái hóa nang ở thời điểm chẩn đoán. Tuy có giá trị cao trong phát hiện khối u, nhưng trên hình ảnh cắt lớp vi tính khó có thể phân biệt được u GIST da dày với khối u khác của vùng dạ dày, đặc biệt là ung thư da dày. Vì thế, cần có thêm những phương tiện khác hỗ trợ thêm giúp cho việc chẩn đoán u rõ ràng hơn, đặc biệt là nội soi và sinh thiết khối u.

Nội soi ống tiêu hóa bao gồm nội soi thực quản - dạ dày - tá tràng và nội soi đại trực tràng thường được tiến hành khi làm chẩn đoán ở những bệnh nhân đã có triệu chứng của hệ tiêu hóa như xuất huyết tiêu hóa, đau bụng, thiếu máu hay sờ thấy u trong ổ bụng. Nghiên cứu của chúng tôi cho thấy trên hình ảnh nội soi dạ dày các khối u có loét niêm mạc chảy máu $52,0 \%$. Vị trí khối u ở hang vị $48,0 \%$, thân vị $26,0 \%$, bờ cong lớn $21,0 \%$, tâm vị $14,0 \%$, bờ cong nhỏ $8,0 \%$, môn vị $2,0 \%$. Kết quả này tương tự như nhận xét về hình thái tổn thương trong nội soi của GIST được ghi nhận trong y văn $[1,4,5]$. Các tác giả đều thống nhất rằng do GIST phát triển từ thành ống tiêu hóa chứ không phải từ lớp niêm mạc nên hình ảnh nội soi thường thấy giống như khối đè đẩy từ ngoài vào. Tổn thương thường được bao phủ bởi một lớp niêm mạc bình thường, đôi khi có thể có loét, tăng sinh mạch hay chảy máu do u chèn ép gây thiếu máu cục bộ vùng niêm mạc ở vị trí tương ứng. Tuy nhiên, hình ảnh nội soi chỉ mang tính chất gợi ý chứ không thể phân biệt được GIST với các tổn thương ngoài niêm mạc khác như u lympho hay u cơ trơn. Như vậy, chẩn đoán xác định vẫn phải dưa vào kết quả giải phẫu bênh, một xét nghiệm có vai trò quyết định trong chẩn đoán bệnh $[1],[2],[3],[6]$.

Hóa mô miễn dịch được coi là tiêu chuẩn vàng để chẩn đoán phân biệt GIST với một số u trung mô khác của đường tiểu hóa. Trong nghiên cứu của chúng tôi, tất cả các bệnh nhân đều được xét nghiệm hóa mô miễn dịch $C D 117$ và các dấu ấn khác DOG1, CD34, Desmin, SMA, S100, CK. Kết quả nghiên cứu của chúng tối cho thấy tî lệ các dấu ấn miễn dịch dương tính với $\mathrm{CD} 117$ và $\mathrm{CD} 34$ đều $100 \%$, DOG1 92,0\%, SMA (88,0\%, Desmin 36,0\%, S100 16,0\%, CK 14,0\%. Nhiêuu nghiên cứu cho thấy tî lệ CD117 dương tính chiếm 90-95\%, CD34 dương tính 60 - 85\%, $30-40 \%$ dương tính với SMA, chỉ $5 \%$ dương tính với $S 100$, và $1-2 \%$ dương tính với Desmin [3]. Như vậy, kết quả nghiên cứu của chúng tôi cho thây các kết quả dương tính cao hơn với các dấu ấn miễn dịch; trong đó, DOG1 là một dấu ấn miễn dịch mới có giá trị rất cao trong chẩn đoán GIST, DOG1 được cho là nhạy hơn và đặc hiệu hơn cả CD117 [7] . Kết quả này có thể do sự phát triển của y học và trình độ chuyên môn của bác sĩ đem lại kết quả chính xác hơn trong chẩn đoán u GIST chính vì vậy tỉ lệ dương tính của các dấu ấn miễn dịch đặc hiệu cúng cao hơn.

Phẫu thuật vẫn là phương pháp có vai trò chủ đạo trong điều trị u GIST. Trong nghiên cứu của chúng tôi, có 5 bệnh nhân $(10,0 \%)$ được mổ cấp cứu, 45 bệnh nhân $(90,0 \%)$ mổ phiên. Trong 5 trường hợp mổ cấp cứu có 4 trường hợp do xuất huyết tiêu hóa và 1 trường hợp có biến chứng thủng dạ dày dẫn đến viêm phúc mạc. Tuy nhiên, sau khi phẫu thuật các trường hợp này đều cho kết quả điều trị tốt, không có trường hợp nào bị biến chứng nặng hay tử vong. Phần lớn bệnh nhân trong nghiên cứu của chúng tôi được mổ mở $76,0 \%$ và trong số $24 \%$ mổ nội soi khổng có bệnh nhân nào phải chuyển mổ mở. Trong thực tế, phương pháp phẫu thuật được lựa chọn phụ thuộc vào nhiều yếu tố như vị trí, kích thước khối u, tình trạng của bệnh nhân cũng như điều kiện trang thiết bị hiện có và khả năng, kinh nghiệm của phẫu thuật viên. Gần đây, phẩu thuật nội soi đang từng bước được chỉ định rộng rãi hơn nhưng còn hạn chế ở những trường hợp kích thước u lớn do nguy cơ làm võ u và phát tán tế bào ung thư vào ổ bụng $[1,8]$.

Trong nghiên cứu của chúng tôi, có 2 bệnh nhân $(4,0 \%)$ chảy máu trong mổ và không thấy các tai biến khác trong mổ. Trong 2 bệnh nhân này, chảy máu trong mổ do khối u lớn và dính vào các tạng, tuy nhiên cả 2 trường hợp đều được cầm máu tốt và không có nguy hiểm. Tỉ lê này cũng thấp hơn so với một số nghiên cứu về phâuu thuật dạ dày khác. Tai biến này có thể liên quan đến việc đánh giá trước mổ, đặc điểm khối u và trình đồ phẫu thuât viên. Đắc biệt chảy máu trong mổ có thể nguy hiểm với những bệnh nhân có bệnh lý tim mạch hoặc những bệnh nhân được mổ nội soi. Vì vậy, đánh giá các bệnh lý kèm theo và lựa chọn phương pháp phẫu thuật phù hợp là quan trọng ảnh hưởng đến kết quả phẫu thuật u GIST [1].

Trong nghiên cứu của chúng tôi, phần lớn bênh nhân trung tiện trở lại vào ngày thứ 1 đến ngày thứ 2 . Thời gian dùng thuốc giảm đau phần 
lớn trong 2 ngày đầu. Thời gian rút sonde dạ dày và cho ăn trở lại trung bình của bệnh nhân trong nghiên cứu là 2,5 ngày và 3,2 ngày. Như vậy, giống với các phẫu thuật đường tiêu hóa khác, thời gian có lại lưu thông ruột thường chậm hơn những phẫu thuật khác trong ổ bụng như cắt túi mật, cắt ruột thừa. Cho ăn trở lại càng sớm càng tốt khi tình trạng bệnh nhân ổn định và có lại lưu thông ruột là biện pháp hiệu quả giúp đảm bảo dinh dưỡng cho bệnh nhân và giảm thời gian nằm viện.

Tuy nhiên, kết quả lâu dài và tái phát của u GIST dạ dày còn chưa được đánh giá đầy đủ. Theo nghiên cứu của Chairat Supsamutchai và cộng sự cho thấy tỉ lệ tái phát là $29,4 \%$ với thời gian theo dõi là 32 tháng [8]. Vì vậy, cần có những nghiên cứu sâu hơn để đánh giá kết qua lâu dài của phẫu thuật u GIST dạ dày.

\section{KẾT LUÂN}

Bệnh nhân u mô đệm dạ dày thường có các triệu chứng lâm sàng không điển hình trong đó đau bụng là triệu chứng thường gặp nhất. Hình ảnh cắt lớp vi tính và nội soi dạ dày có giá trị cao trong chẩn đoán tuy nhiên chẩn đoán xác định phải dựa vào giải phẫu bệnh và hóa mô miễn dịch đặc biệt 2 dấu ấn CD117 và CD34. Phẫu thuật có kết quả sớm thường tốt, tuy nhiên về lâu dài cần theo dõi và đánh giá thêm.
1. Al-Kalaawy, M., et al., Gastrointestinal stroma tumors (GISTs), 10-year experience: Patterns of failure and prognostic factors for survival of 127 patients. Journal of the Egyptian National Cancer Institute, 2012. 24(1): p. 31-39.

2. Poškus, E., et al., Surgical management of gastrointestinal stromal tumors: a single center experience. Videosurgery and Other Miniinvasive Techniques, 2014. 9(1): 71-82.

3. Kang, Y.-K., et al., Clinical practice guideline for accurate diagnosis and effective treatment of gastrointestinal stromal tumor in Korea. Journal of Korean medical science, 2010. 25(11): p. 1543-1552.

4. Bùi Trung Nghĩa (2011), Đánh giá đặc điểm lâm sàng, câan lâm sàng và kêt quả điểu trị phấu thuật u mô đệm đường tiêu hóa (GIST) tai bênh viển Việt đức từ tháng 01/2005 - 12/2010. Luận văn tốt nghiêp bác sĩ nôii trú, Trường Đai hoc Y Hà Nội.

5. Mai Trọng Khoa, Trân Đình Hà, Phạm Cẩm Phương và cs (2014), Đánh giá hiệu quả của Imatinib (Glivec) trong điều trị U mô đệm đường tiêu hóa tại Trung tâm $Y$ học hạt nhân và Ung bướu - Bệnh viên Bach Mai, in Tạp chí Ung Thư hoc Việt Nam. 2014, tr. 41-47.

6. Diệp Bảo Tuấn (2016), Nghiên cứu chẩn đoán và điêuu trị bướu mô đệm đường tiêu hóa, Tạp chí Ung thư học Việt Nam. 2 (GIST), 7.

7. Phạm Minh Hải, Lê Quan Anh Tuấn, Võ Tấn Long và CS (2008), Đặc điểm lâm sàng, cận lâm sàng và kết quả điêu trị phẫu thuật u mồ đệm đường tiêu hóa. Tap chỉ Nghiên cứu Y học TP Hồ Chí Minh, 4 (Phụ bản số 4 ), 70.

8. Supsamutchai, C., et al. (2018), A cohort study of prognostic factors associated with recurrence or metastasis of gastrointestinal stromal tumor (GIST) of stomach. Annals of Medicine and Surgery, 35: p. 1-5.

\section{TÀI LIỆU THAM KHẢO}

\section{TỨ VẬT ĐÀO HỒNG THANG KẾT HỢP ĐIỆN CHÂM ĐIỀU TRI ĐAU THẮT LƯNG DO THOÁI HÓA CộT SỐNG}

\section{TÓM TẮT}

Mục tiêu: đánh giá hiệu quả giảm đau, cải thiện chức năng vận động cột sống trên bệnh nhân đau thắt lưng do thoái hóa cột sống bằng bài thuốc Tứ vật đào hồng thang kết hợp điện châm. Đối tượng và phương pháp: 68bệnh nhân được chẩn đoán đau thắt lưng do thoái hóa cột sống, không phân biệt giới tính, nghề nghiệp, tình nguyện tham gia nghiên cứu. Nhóm nghiên cứu điều trị bằng bài thuốc Tứ vật đào hồng thang kết hợp điện châm, nhóm đối chứng điêu

${ }^{1}$ Viện Y học cổ truyền Quân đội,

²Bềnh viện Châm cứu Trung ướng

Chịu trách nhiệm chính: Nguyễn Vinh Quốc

Email: quocnguyenvinh@gmail.com

Ngày nhận bài: 4/7/2021

Ngày phản biên khoa hoc: 30/7/2021

Ngày duyệt bài: 23/8/2021

\section{Nguyễn Vinh Quốc ${ }^{1}$, Nguyễn Đức Minh ${ }^{2}$}

trị bằng điện châm đơn thuân. So sánh kết quả trước và sau điều trị. Kết quả: Bài thuốc Tứ vật đào hồng thang kết hợp điện châm hiệu quả tốt trong điều trị đau thắt lưng do thoái hóa cột sống, $67,6 \%$ đat kết quả tốt. Điểm VAS tăng từ 1,62 (điểm) trước điêuu trị lên3,79 (điểm) sau điêu trị; độ giãn cột sống thắt lưng tăng từ 12,34 $(\mathrm{cm})$ trước điều trị lên 14,23 $(\mathrm{cm})$ sau điều trị; tâm vận động cột sống thắt lưng các động tác cải thiện tốt hởn có ý nghĩa so với trước điều trị và tốt hơn so với nhóm đối chứng. Kết luân: Bài thuốc Tứ vật đào hồng thang kết hợp điện châmhiệu quả tốt trong điều trị đau thắt lưng do thoái hóa cột sống.

Tư khóa: Tứ vật đào hồng thang, điện châm, thoái hóa cột sống thắt lưng

\section{SUMMARY \\ THE EFFECTS OF TREATMENT OF LOW BACK PAIN CAUSED BY DEGENERATIVE SPINE BY "TU VAT DAO HONG THANG" COMBINED WITH}

